\title{
Safety and efficacy of simultaneous use of Mifepristone and Misoprostol in second trimester termination of pregnancy
}

\author{
Sayali Shripad Jahagirdar*, Pushpa Shankarrao Junghare
}

Department of Obstetrics \& Gynaecology, Dr. PDMMC, Amravati, Maharashtra, India

Received: 17 July 2015

Revised: 26 August 2015

Accepted: 29 August 2015

\section{*Correspondence:}

Dr. Sayali Shripad Jahagirdar,

E-mail: rupasi2001@yahoo.co.in

Copyright: (c) the author(s), publisher and licensee Medip Academy. This is an open-access article distributed under the terms of the Creative Commons Attribution Non-Commercial License, which permits unrestricted non-commercial use, distribution, and reproduction in any medium, provided the original work is properly cited.

\begin{abstract}
Background: Combination of Mifepristone and Misoprostol has been successfully used for termination of pregnancy up to 63 days however no specific protocol is available for use in termination of pregnancy in second trimester. There are various regimens regarding optimal dose of Mifepristone and Misoprostol to be used in second trimester termination of pregnancy. Most of the regimens have a 24 to $48 \mathrm{hr}$. interval in administering the two drugs.

Methods: This is a non-randomized prospective single arm interventional study approved by ethical committee of our institution and carried out over a period of 2 years from January 2013 to December 2014.This trial was also registered under Clinical Trial Registry Of India CTRI/2013/03/003488.152 healthy women who wanted to undergo second trimester termination of pregnancy were included in the study after applying inclusion and exclusion criteria. All women received T Mifepristone $200 \mathrm{mg}$ orally along with $\mathrm{T}$ Misoprostol $400 \mathrm{mcg}$ placed vaginally in the posterior fornix. T Misoprostol $200 \mathrm{mcg}$ was placed vaginally every $4 \mathrm{hrs}$ till good uterine contractions were established. The end point of the study was complete abortion with expulsion of placenta. The induction abortion interval was noted. Women were observed for complications and women needing additional intervention to complete the abortion process were also noted.

Results: The mean induction abortion interval was 783.17 minutes (13 hrs.) in our study which was comparable to similar study by Chai $\mathrm{J}$ et al in which induction-to-abortion interval was 10 hours $96 \%$ of women aborted in 24 hrs. and $100 \%$ in $32 \mathrm{hrs}$. in our study. $81 \%$ had no complications and 17\% had minor complications which were managed by medicines alone.

Conclusions: Simultaneous use of Mifepristone and misoprostol is both safe and effective in termination of pregnancy in second trimester.
\end{abstract}

Keywords: Misoprostol, Mifepristone, Second trimester termination of pregnancy

\section{INTRODUCTION}

Combination of Mifepristone and Misoprostol has been successfully used for termination of pregnancy up to 63 days however no specific protocol is available for use in termination of pregnancy in second trimester. Mifepristone (RU-486) is a synthetic steroidal anti progestogen and antiglucocorticoid drug. ${ }^{1}$ In presence of progesterone, mifepristone acts as a competitive progesterone receptor agonist. ${ }^{2}$ In regimes used for medical abortion, mifepristone blocks progesterone receptors causing endometrial decidual degeneration, cervical softening and dilatation, release of endogenous prostaglandins and an increase in sensitivity of the myometrium to the contractile effects of prostaglandins. ${ }^{2}$ After oral administration of a single dose of $200 \mathrm{mg}$, mifepristone is rapidly absorbed and peak concentration is reached in $1.3 \mathrm{hrs}$. Misoprostol is a synthetic prostaglandin E1 analogue that is used for a variety of indications in the practice of obstetrics including medical 
abortion, induction of labor, cervical ripening before uterine evacuation and treatment and prevention of postpartum haemorrhage. The effect of Misoprostol is dose dependant and includes cervical softening and dilatation, uterine contractions, nausea, vomiting, diarrhoea, fever and chills. To study the efficacy and safety of simultaneous use of Mifepristone and Misoprostol for termination of pregnancy in second trimester (13-20) weeks.

\section{METHODS}

This is a non-randomized prospective single arm interventional study approved by ethical committee of our institution and carried out over a period of 2 years from January 2013 to December 2014. This trial was also registered under Clinical Trial Registry of India CTRI/2013/03/003488. 152 healthy women who wanted to undergo second trimester termination of pregnancy were included in the study after applying inclusion and exclusion criteria.

\section{Inclusion criteria}

1. Age between 15- 45 yrs.

2. Gestation period between 13-20 weeks

3. $\mathrm{Hb}>8 \mathrm{gm} / \mathrm{dl}$

\section{Exclusion criteria}

1. Women with known hypersensitivity to Mifepristone or misoprostol.

2. Women with medical renal disease, heart disease, severe anemia, chronic adrenal failure, porphyria's, epilepsy were excluded from the study.

Before termination all women underwent general physical and gynaecological examination. Gestational age was determined using date of last menstrual period in women having regular menstrual cycles and ultrasound was used where clinical examination did not correspond with dates. Haemoglobin estimation, blood grouping and $\mathrm{Rh}$ typing were done for all women. Those with $\mathrm{Rh}$ negative blood group were given anti- D immunoglobulin $300 \mathrm{mcg}$ within $24 \mathrm{hrs}$. of termination of pregnancy. The criteria for second trimester termination of pregnancy were all those included under the MTP Act 1971 and intrauterine fetal demise between 13-20 weeks of gestation. All women after admission in ward received $\mathrm{T}$ Mifepristone $200 \mathrm{mg}$ orally along with $\mathrm{T}$ Misoprostol $400 \mathrm{mcg}$ placed vaginally in the posterior fornix. Patient was monitored for frequency and intensity of uterine contractions and Bishops score was assessed 4 hourly. Intravenous antibiotics were administered after vaginal misoprostol. T Misoprostol $200 \mathrm{mcg}$ was placed vaginally every $4 \mathrm{hrs}$ till good uterine contractions were established. The end point of the study was complete abortion with expulsion of placenta. The induction abortion interval defined as the time between administrations of the first Misoprostol until expulsion of fetus was noted. Rate of successful abortion was defined as complete evacuation using the two drugs without using any additional intervention within 24 hours of induction. Two patients who failed to abort within $24 \mathrm{hrs}$. of induction and needed some other method for termination were excluded from the study. Women were observed for complications such as fever on 2 or more occasions, headache, profuse bleeding and hypotension. Patients needing additional intervention to complete the abortion process like curettage, manual removal of placenta, augmentation with Pitocin were also noted.

\section{RESULTS}

Table 1: Age of women.

\begin{tabular}{|lll|}
\hline Age & No of woman & Percentage \\
\hline $15-19$ yr. & 10 & 6.7 \\
\hline $20-24$ yr. & 50 & 33.3 \\
\hline $25-29$ yr. & 46 & 30.7 \\
\hline $30-34$ yr. & 30 & 20.0 \\
\hline $35-39$ yr. & 11 & 7.3 \\
\hline $40-44$ yr. & 3 & 2.0 \\
\hline Total & 150 & 100.0 \\
\hline
\end{tabular}

Table 2: Gravidity of women.

\begin{tabular}{|lll|}
\hline Gravida & No of women & Percent \\
\hline 1 & 60 & 40.0 \\
\hline 2 & 27 & 18.0 \\
\hline 3 & 49 & 32.7 \\
\hline 4 & 11 & 7.3 \\
\hline 5 & 3 & 2.0 \\
\hline Total & 150 & 100.0 \\
\hline
\end{tabular}

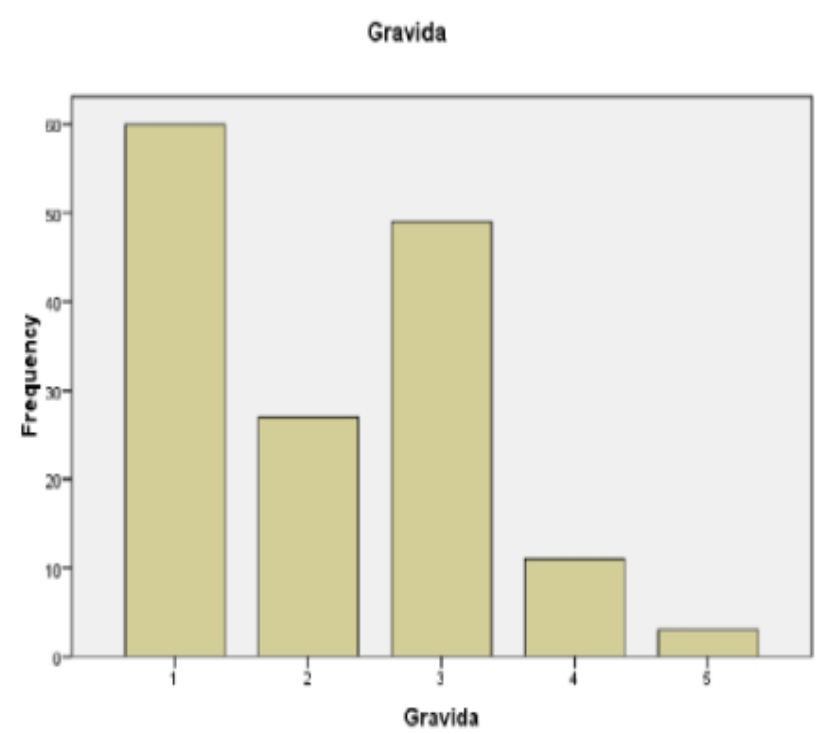

Figure 1: Graph showing gravidity and no. of women. 


\section{Age distribution}

1. $84 \%$ of the women were in the age group 20-34 yrs.

2. The minimum age of woman was $16 \mathrm{yrs}$.

3. Maximum age of woman was $42 \mathrm{yrs}$.

4. The mean age of women was $26.77 \mathrm{yrs}$.

\section{Gravidity}

1. $40 \%$ women were primigravida

2. $10 \%$ were unmarried

3. $2 \%$ were grand multipara

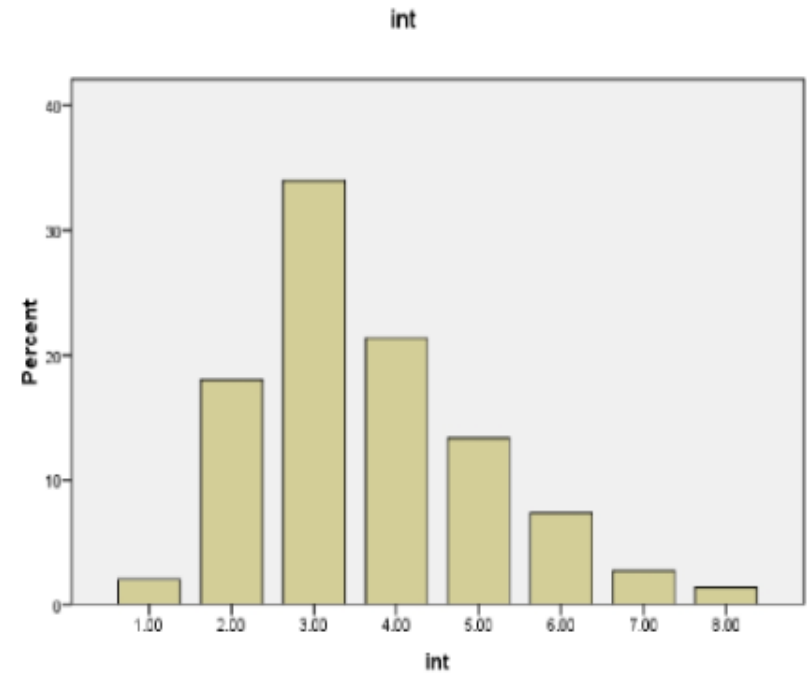

Figure 2: Graph showing induction abortion interval and no. of women.

Table 3: Induction abortion interval and no. of women.

\begin{tabular}{|llll|}
\hline $\begin{array}{l}\text { I-A } \\
\text { interval }\end{array}$ & $\begin{array}{l}\text { No of } \\
\text { women }\end{array}$ & Percent & $\begin{array}{l}\text { Cumulative } \\
\text { Percent }\end{array}$ \\
\hline 4 hrs. & 3 & 2.0 & 2.0 \\
\hline 8 hrs. & 27 & 18.0 & 20.0 \\
\hline 12 hrs. & 51 & 34.0 & 54.0 \\
\hline 16 hrs. & 32 & 21.3 & 75.3 \\
\hline 20 hrs. & 20 & 13.3 & 88.7 \\
\hline 24 hrs. & 11 & 7.3 & 96.0 \\
\hline 28 hrs. & 4 & 2.7 & 98.7 \\
\hline 32 hrs. & 2 & 1.3 & 100.0 \\
\hline Total & 150 & 100.0 & \\
\hline
\end{tabular}

Table 4: Induction abortion interval and no. of women.

\begin{tabular}{|lll|}
\hline I-A interval & No of women & Percent \\
\hline Up to16 hrs. & 113 & 75.3 \\
\hline Beyond 16 hrs. & 37 & 24.7 \\
\hline Total & 150 & 100.0 \\
\hline
\end{tabular}

\section{Induction abortion interval}

1. Women who had IA interval of more than $16 \mathrm{hrs}$ were mostly having anomalous baby $(48 \%)$ or were unmarried (16\%).

2. All women having IUD aborted within $16 \mathrm{hrs}$.

\section{Complications}

1. $80.7 \%$ had no complications.

2. $17 \%$ had minor complications which were managed by medicines alone.

3. 2 Pts required blood transfusion and 3 required manual removal of placenta.

4. No major complications were seen in our study. Of the 2 patients who failed to abort one required emcredil instillation and the other underwent hysterectomy.

5. There was no case of uterine rupture.

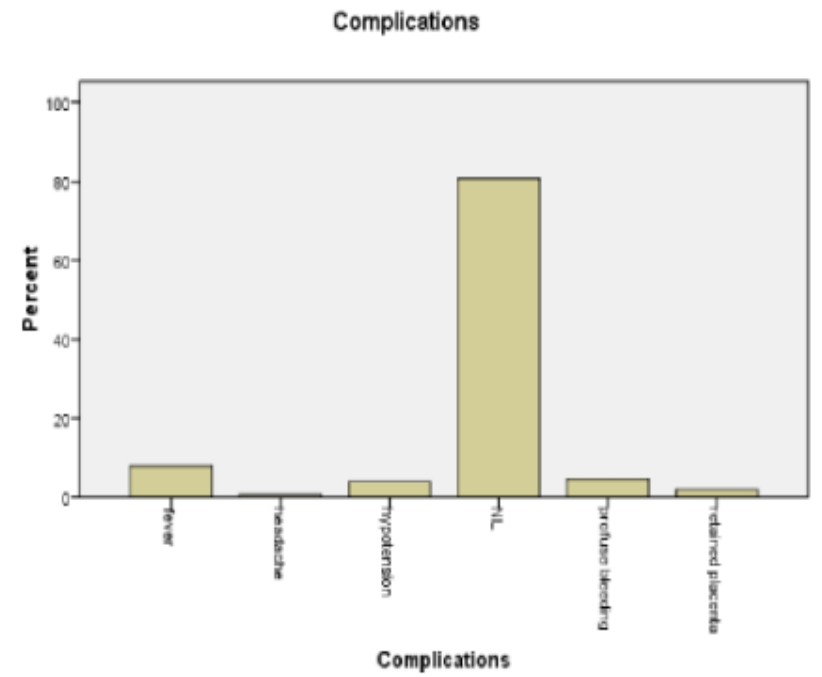

Figure 3: Graph showing complications and their frequency.

\section{Interventions required}

1. In $60 \%$ of women abortion was complete.

2. Surgical curettage had to be done in $18 \%$ women.

\section{DISCUSSION}

The mean induction abortion interval was 783.17 minutes (13 hrs.) in our study which was comparable to study by Chai $J$ et al in which the simultaneous use of Mifepristone and Misoprostol was associated inductionto-abortion interval of 10 hours. ${ }^{3} 75 \%$ of women aborted in 16 hrs. $96 \%$ of women aborted in 24 hrs. and $100 \%$ in $32 \mathrm{hrs}$. in our study. These results show better efficacy of this regime as compared to results of largest cohort study of 1,002 women having second-trimester medical abortion using the recommended Mifepristone and misoprostol regimen (24-36 hrs.) interval between both 
drugs) where the complete expulsion rate was 98.3 percent at 24 hours and 99.2 percent at 36 hours. ${ }^{4}$ If medical or social issues require a shorter time interval between taking Mifepristone and starting misoprostol, the interval may be shortened or the medications started simultaneously. Even if Mifepristone is taken at the same time as misoprostol, the combined regimen is more effective than misoprostol alone. ${ }^{2}$ The recommended time interval between Mifepristone and the first dose of misoprostol has been $36-48 \mathrm{~h}$, as the maximal effect of
Mifepristone is reached at that point (Gemzell-Danielsson and Lalitkumar, 2008). ${ }^{5}$ However, in clinical practice this waiting time poses several problems like the possible anxiety of aborting at home following Mifepristone administration.

Table 5: Induction abortion interval and indication of termination of pregnancy.

\begin{tabular}{|lllllllll|}
\hline I-A interval & IUD & anomaly & $\begin{array}{l}\text { bleeding } \\
\text { pv }\end{array}$ & divorce & $\begin{array}{l}\text { failure of } \\
\text { contraception }\end{array}$ & leaking pv & medical disorder & social \\
\hline Up to 12 hrs. & 11 & 23 & 4 & 5 & 20 & 3 & 7 & 31 \\
\hline $12-24$ hrs. & 0 & 18 & 1 & 0 & 2 & 0 & 3 & 7 \\
\hline Total & 11 & 41 & 5 & 5 & 22 & 3 & 10 & 38 \\
\hline
\end{tabular}

Table 6: Frequency of complications.

\begin{tabular}{|lll|}
\hline Complications & No of woman & Percentage \\
\hline fever & 12 & 8.0 \\
\hline headache & 1 & 7 \\
\hline hypotension & 6 & 4.0 \\
\hline NIL & 121 & 80.7 \\
\hline profuse bleeding & 7 & 4.7 \\
\hline retained placenta & 3 & 2.0 \\
\hline Total & 150 & 100.0 \\
\hline
\end{tabular}

Table 7: Type of intervention and their frequency.

\begin{tabular}{|lll|}
\hline Intervention & No of women & Percentage \\
\hline MRP & 26 & 17.3 \\
\hline NIL & 2 & 1.3 \\
\hline Pitocin & 89 & 59.3 \\
\hline Pitocin + CC & 2 & 20.8 \\
\hline Total & 150 & 1.3 \\
\hline
\end{tabular}

In our trial there was no case of uterine rupture. In a meta-analysis of studies of medical abortion, the overall rate of uterine rupture is 0.08 percent, with a rate of 0.28 percent in women with a previous cesarean section. ${ }^{6}$ History of curettage, fetal indication, increasing age and 2-day interval between Mifepristone and misoprostol increase the risk of surgical evacuation in cases of second trimester medical termination of pregnancy. The rate of surgical evacuation was $30.8 \%$ in a similar study done by Mentula $\mathrm{M}$ et al in $2010 .^{7}$ This regimen is effective in management of women having intrauterine fetal demise. The amount of Misoprostol required was less in these patients as compared to others. ${ }^{8}$

\section{CONCLUSIONS}

Simultaneous use of Mifepristone and misoprostol is safe and effective in termination of pregnancy in second trimester.

\section{Funding: No funding sources}

Conflict of interest: None declared

Ethical approval: The study was approved by the Institutional Ethics Committee

\section{REFERENCES}

1. Safe abortion: Technical and policy guidance for health systems (2nd ed.) Geneva: World Health Organization, 2012.

2. Ngoc NT, Shochet $T$, Raghavan $S$, et al. Mifepristone and misoprostol compared with misoprostol alone for second-trimester abortion: a randomized controlled trial Obstet Gynecol. 2011;118(3):601-8.

3. Chai J, Tang OS, Hong QQ, et al. A randomized trial to compare two dosing intervals of misoprostol following Mifepristone administration in second trimester medical abortion. Human Reproduction. 2009;24(2),320-324.

4. Ashok P, Templeton A, Wagaarachchi P, Flett G. Midtrimester medical termination of pregnancy: a review of 1002 consecutive cases. Contraception. 2044;69(1):51-58.

5. Gemzell-Danielsson $\mathrm{K}^{1}$, Lalitkumar S.Second trimester medical abortion with MifepristoneMisoprostol and Misoprostol alone: a review of methods and management. Reprod Health Matters. 2008;16(31):162-72. 
6. Goyal, V. Uterine rupture in second-trimester misoprostol-induced abortion after cesarean delivery: A systematic review. Obstetrics and Gynecology. 2009;113(5),1117-1123.

7. Mentula M, Heikinheimo O. Risk factors of surgical evacuation following second-trimester medical termination of pregnancy. Contraception. 2012;86(2):141-6
8. Sharma D, Singhal SR, Poonam, Paul A, Kunika. Comparison of Mifepristone combination with misoprostol and misoprostol alone in the management of intrauterine death: condensation misoprostol and Mifepristone combination is more effective than misoprostol alone in the management of intrauterine death. Taiwan J Obstet Gynecol. 2011;50(3):322-5.

Cite this article as: Jahagirdar SS, Junghare PS. Safety and efficacy of simultaneous use of Mifepristone and Misoprostol in second trimester termination of pregnancy. Int J Reprod Contracept Obstet Gynecol 2015;4:1359-63. 